\title{
The future of in-store technology
}

\section{Dhruv Grewal $^{1} \cdot$ Stephanie M. Noble ${ }^{2} \cdot$ Anne L. Roggeveen $^{3} \cdot$ Jens Nordfalt $^{4}$}

Published online: 11 October 2019

(C) The Author(s) 2019

\begin{abstract}
This paper introduces a conceptual framework for understanding new and futuristic in-store technology infusions. First, we develop a $2 \times 2$ typology of different innovative and futuristic technologies focusing on their level of convenience and social presence for the consumer. Next, we offer a series of propositions based on the idea that convenience and social presence can trigger vividness by enhancing consumer involvement, imagery, and elaboration, which ultimately leads to enhanced sales. Finally, the paper then focuses on four moderating areas - consumer traits, product/service dimensions, mental models and social networks - to understand how they might impact the vividness experienced via the technology.
\end{abstract}

Keywords In-store technology $\cdot$ Convenience $\cdot$ Social presence $\cdot$ Retailing $\cdot$ Services

\section{Introduction}

We are amid a technological retail revolution. There are an increasing number of technologies available to retailers and service providers that have the potential to enhance both their operations and the experience they can provide customers. Companies that embrace the opportunities and experiment with the technologies, to determine which technologies best enhance operational efficiency and which best enhance the customer experience, are likely to be the most successful. In

All authors contributed towards the writing of the paper. Mark Houston served as accepting editor for this article.

Jens Nordfalt

J.G.Nordfalt@bath.ac.uk

Dhruv Grewal

dgrewal@babson.edu

Stephanie M. Noble

snoble4@utk.edu

Anne L. Roggeveen

aroggeveen@babson.edu

1 Babson College, 213 Malloy Hall, Babson Park, MA 02457, USA

2 University of Tennessee, 310 Stokely Management Center, Knoxville, TN 37996-0530, USA

3 Babson College, 215 Malloy Hall, Babson Park, MA 02457, USA

4 University of Bath, Claverton Down, Bath BA2 7AY, UK this paper, we focus on how these new and futuristic in-store technologies can impact the customer experience.

The in-store experience is part of the customer journey (Lemon and Verhoef 2016) and technologies can serve as important touch points to customers, as well as assist and augment frontline employee (FLE) tasks. These new and futuristic technologies can change the customer experience by making the shopping experience more convenient, changing how the customer shops, and/or changing their interactions with FLEs. While companies continually implement new technologies, the expectations customers come to hold regarding those technologies evolve. Many technologies that were the delighters of yesterday have become the satisfiers of today. For example, today's customers assume an integrated omni-channel experience where they can order online and pick up in the store. Another satisfier of today is having free Wi-Fi in the store.

But, for retailers to stand out and be on the cutting edge, they must carefully consider what will delight customers. In today's socially connected world, we anticipate that many consumers seek social engagement and interactive experiences on platforms that facilitate a sense of connection (Hyder 2014; Pew Research Center 2010; Redmond 2017). Consumers have a strong desire for social presence (Donald 1991, Granovetter 1985). Social presence means the felt presence of others. It does not mean that someone else must be physically present. Social presence might come via reading posts from other customers about the product/service on social media or videochatting with a friend while shopping in the store. 
Recognizing that customers desire a convenient, easy, frictionless experience, as well as the desire for social presence allows retailers to experiment and test new technologies which will enhance the customer experience in the store on these dimensions. For example, Amazon Go stores allow consumers to simply pick up items without needing to stop at the check-out (AI and cameras capture the purchase and charge the consumer); thus, enhancing convenience. Other retailers and service providers focus on enhancing the felt social presence. For example, H\&M has installed voice interactive mirrors in their New York City flagship store. Those mirrors "wake up" when someone looks at it long enough and offers selfies, style advice, and discounts.

In this research, we create a typology of different innovative and futuristic technologies focusing on their level of convenience and social presence for the consumer. Convenience signifies the reduced time and effort consumers must exert to buy or use products and services, due to the assistance of technology (Berry et al. 2002). Social presence refers to the degree to which the technology causes consumers to sense that they are in the presence of others (van Doorn et al. 2017), which might result from interactions with the machine itself (e.g., robots) (Heerink et al. 2010; van Doorn et al. 2017), human connections supported by the technology (Zhu, Benbasat and Jiang 2010) (e.g., social media posts, collaborative online shopping), or some technology feature that humanizes the brand (Schroll et al. 2018). Using high and low levels of convenience and social presence, we build a $2 \times 2$ typology. This typology is derived based on interviews with key informants in the retail sector and triangulated with existing literature. Interviews took place on the phone and ranged from 30 to $45 \mathrm{~min}$. The seven interview respondents were from the following companies: PTC (Senior Director), Clas Ohlson (Key Account Manager), H\&M (Business Development Project Manager), Ombori Group (CEO), AB Processverkstad 17 (Retail Management Consultant), Coop (Head of Insights, Analytics, and Intelligence), and ICA Gruppen (Head of ICAx). Respondents spoke of retail technologies they created, supplied, beta tested, or used (e.g., in a flagship store) which helped inform the dimensions of our typology. It is important to note that although we present the quadrants as high and low levels of convenience and social presence, each of these dimensions vary on a continuum with no definitive cut-off point.

After introducing this typology, we then offer a series of propositions based on the idea that convenience and social presence have the potential to make the product experience more vivid to customers - due to enhanced consumer involvement, imagery, and/or elaboration. This vividness, in turn, is expected to increase the likelihood of a consumer purchasing the product/ service (Nisbett and Ross 1980). We also offer propositions regarding four moderating areas - consumer traits, product/ service dimensions, mental models and social networks.
This research thus offers three significant contributions. First, our proposed in-store technology infusion typology details specific combinations of technology-enabled convenience and social presence and locates several current and emerging technologies within this typology. Second, we outline a conceptual framework to link in-store technology infusion with desirable retailer and service provider outcomes through mechanisms that reflect vividness theory, including involvement, imagery, and elaboration. This framework also features four moderators that can enhance the impact of instore technology infusion on purchase intentions: consumer traits, product/service dimensions, mental models, and social networks. Third, we offer several propositions regarding the impact of new and futuristic in-store technology infusion, especially when it evokes high levels of convenience and social presence. These propositions in turn constitute an agenda for further research.

\section{Typology of new and futuristic in-store technology infusion}

In building our typology of new technologies (see Fig. 1), we focus on two dimensions from the consumer perspectiveconvenience and social presence. Additionally, we predominantly focus on how in-store technology touchpoints can impact the customer journey (Lemon and Verhoef 2016). This is important because $90 \%$ of retail sales continue to take place in brick-and-mortar stores; online sales account for less than $10 \%$ of total retail sales (Danziger 2017). To develop a more complete understanding of convenience and social presence, we first discuss existing literature related to these factors.

\section{Convenience}

Copeland (1923) initially classified products that required minimal effort to purchase as "convenience goods." As additional dimensions of convenience have emerged, the basic idea remains that, in many shopping situations, consumers seek to minimize the time and effort they devote to shopping (Berry et al. 2002; Seiders et al. 2005).

We examine convenience benefits that stem from use of instore technologies. ${ }^{1}$ There are five distinct dimensions of service convenience: decision, access, transaction, benefit, and post-benefit (Berry et al. 2002). Decision convenience pertains to the time and effort needed to reach make-or-buy

\footnotetext{
${ }^{1}$ The technology acceptance model (TAM) shows that perceived usefulness and ease of use of a technology influences attitude and use of it. Our convenience construct explores the convenience benefits that emerge from actual usage of the technology. Therefore, perceived usefulness and ease of use would be antecedents of in-store technology infusion usage and are not components of the convenience benefits that emerge from using the technology (Davis, 1989; Venkatesh and Davis 2000).
} 
Fig. 1 In-store technology infusion

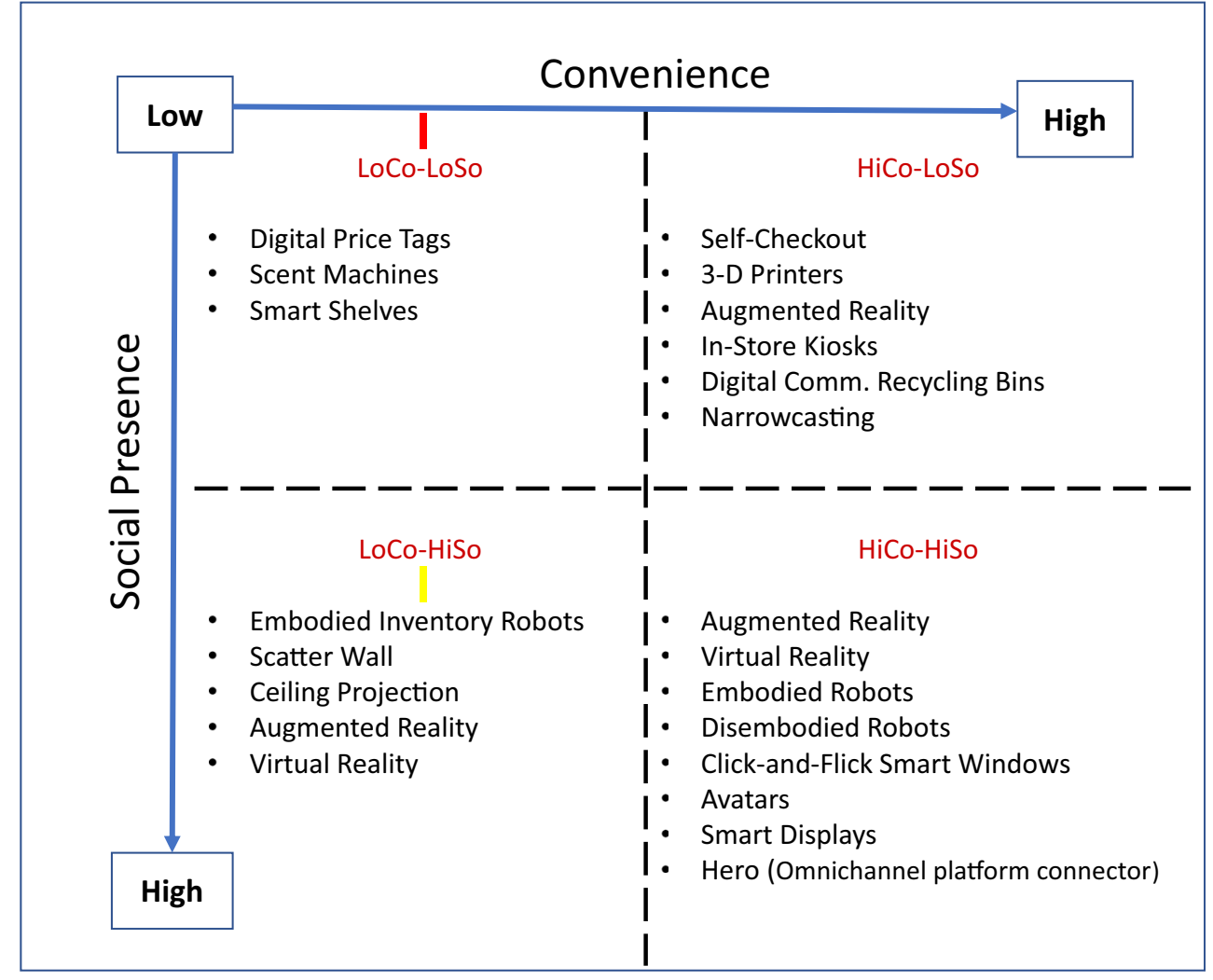

decisions; at Build-a-Bear Workshops for example, consumers can either make their own bears or buy premade versions that offer greater decision convenience benefits. Access convenience instead entails the resources needed to request a service, such as when consumers physically dial a telephone number to order pizza (more effortful) versus using a voiceactivated system (Bandaranayake 2018). Transaction convenience involves payment-related tasks, such as standing in line, completing online registration forms, or entering credit card information. Benefit convenience reflects the resource expenditures needed to experience the core benefit of the product or service, such as locating and evaluating them. Finally, post-benefit convenience refers to the time and effort needed to follow up with a company if the consumer experiences a service failure or needs additional services after the purchase (e.g., maintenance, exchange). Overall, the less time and effort that consumers expend in each area, the more likely it is that their service evaluation will be favorable.

Each type of convenience could be uniquely affected by the infusion of technologies. Technology now enables consumers to explore, shop, and evaluate their experiences in ways that did not exist previously (in-store or in an online environment). For example, augmented and virtual reality allow customers to further explore the product and experience it in different settings, thus, enhancing decision convenience (Heller et al. 2019). 3-D printers can produce customized products providing greater access convenience. Scanning quick response
(QR) codes into a mobile phone to access detailed information about the product enhances benefit convenience. Augmented reality $(A R)$ that depicts products together with virtual elements also increases benefit convenience making it easier for consumers to visualize the output. Post-benefit convenience can be enhanced by using AI to send targeted emails at the time when that individual customer might need to reorder.

\section{Social presence}

Social presence arises when products or situations trigger a feeling that a human being is present (Biocca and Harms 2002; Biocca and Nowak 2001; Heeter 1992). For example, collaborative technological features such as shared website navigation and voice chat features allow consumers to feel the presence of others when shopping online (Zhu et al. 2010). Importantly though, a human being does not need to be physically present for a person to experience a sense of social presence (Dahl et al. 2001). For example, inanimate objects such as handwritten typefaces (Schroll et al. 2018) and robots (van Doorn et al. 2017) have been shown to trigger social presence feelings. Things that signal humanity, warmth, or human involvement are expected to trigger feelings of social presence.

Some technologies can create social presence. Consider how both embodied and disembodied robots can trigger 
human presence feelings (van Doorn et al. 2017). Embodied robots have features which look like humans and thus trigger social presence. Disembodied robots, such as Siri or Alexa, don't look like humans, but can engage in two-way conversations thus enhancing social presence. "Scatter walls" in the stores that display social media posts from consumers around the world create social presence. Virtual reality can also transport consumers into some aspect of the retailer's story enhancing social presence. North Face, for example, offers shoppers (in certain stores) to put on virtual reality glasses and be transported to trekking through Yosemite (Dua 2015). Similarly, the 'Omnistory Ayrton Senna' store in São Paulo uses virtual reality to help consumers connect with Ayrton Senna, a beloved racecar driver, by virtually transporting them into one of his racecars or other interactive experiences with his story (Yamashita 2019).

\section{Technology configurations that produce convenience and social presence}

Building from the ideas of convenience and social presence, we next propose a $2 \times 2$ typology that addresses how different in-store technologies might be categorized. Technologies can move across quadrants as they encompass more levels of a dimension. For example, augmented and virtual reality solutions appear in multiple quadrants, as different companies use these technologies in ways which vary in terms of the degree of convenience and social presence it offers to the customer.

The four quadrants, which will be described in detail below, represent low convenience and low social presence (LoCo-LoSo), high convenience and low social presence (HiCo-LoSo), low convenience and high social presence (LoCo-HiSo), and high convenience and high social presence (HiCo-HiSo). Thinking about how each new technology relates to these dimensions is important for retailers and service providers to consider as they experiment to determine which technologies should be infused in the store. In-store technology possibilities are quite varied (see Table 1) with both service providers (e.g., Marriott, Renew) and retailers (e.g., Sephora, Lowes, IKEA) pioneering technologies. Introducing technology in a store just for the sake of technology is unlikely to impress busy consumers. Rather, the technology should help them achieve an outcome they could not have reached otherwise (or achieve the outcome quickly) and/ or feel a presence of others in the experience.

In the LoCo-LoSo Quadrant, in-store technology infusion scores low on both convenience and social presence. However, it is important to note that low levels of convenience and social presence should not be taken as evidence that the role of these technologies are ineffective. It is important to remember that our typology is considering the technologies from the consumer perspective - do they add convenience and/or social presence for the customer. However, many technologies are also infused into a retailer or service because they offer benefits to the company's operations. Consider digital price tags, scent machines, or smart shelves. Digital price tags, such as those used in the physical Amazon 4-Star Store (see Fig. 2, Panel A), provide no time savings and little effort savings for consumers, but offer operational efficiency for retailers as staff can easily update pricing information. In addition, they do not create social presence. The small convenience savings for customers comes in the fact that the screens can provide rating information and can display lower prices for Prime members (Rubin 2018).

Scent machines, which can subtly introduce a smell into the retail store, can activate olfactory senses and trigger emotional memory (Krishna 2012). They add additional multisensory elements to the retail experience (Spence et al. 2014), helping retailers and services providers distinguish themselves from competitors, but they do not provide enhanced convenience for the consumer or a strong sense of social presence.

Smart shelves have recently incorporated a feature of LED displays that change with shoppers' proximity. When shoppers are far away, the display flashes logos and images to attract them. As the shopper approaches the shelf, the LED images change to highlight product names. When the shopper is at the display, pricing information appears (AWM Smart Shelf 2019; see Fig. 2, Panel B). Although attention grabbing and informative, the shelves offer lower levels of convenience or social presence elements for consumers. Other types of digital signage in stores, such as more traditional digital screens on endcaps, are similarly attention grabbing and can add to the in-store experience (Törn 2018) but, offer lower levels of convenience or social presence elements than technologies in the other quadrants. Again, their value is better captured at the provider level, rather than the consumer level, in that smart shelves and other digital displays help companies draw attention to their products over competitors.

The HiCo-LoSo Quadrant in-store technologies provide strong convenience benefits, but little social presence. These include self-checkout options, 3-D printers, augmented reality (AR) applications, in-store kiosks, digital communication recycling bins, and narrowcasting. Some of these technologies are more established, such as self-checkout options and 3-D printing. Other technologies in this quadrant are newer introductions to the marketplace. For example, digital communication recycling bins, which can be placed in stores, town centers, etc. are traditional recycling bins, with the added feature of being able to track unique identification numbers on consumers' phones. The bins recognize consumers' phones as they walk by and send them retailers' and service providers' targeted advertisements (Ridden 2012; Datoo 2013). Geissler grocery has added in-store kiosks that list recipe ideas, deal promotions, and other types of information; consumers can review the deals and recipes to find ones that meet their needs (Ingram 2017). As these examples illustrate, the technology 
Table 1 In-store technology infusion examples pertaining to quadrants in 2 x 2 typology

Author(s) Retailers Summary of In-Store Technology Infusion

Low Convenience, Low Social Presence (LoCo-LoSo)

Sifferlin (2013)

Rubin (2018); Zhang (2018)

Hugo Boss, Marriott

Amazon 4-star; Fry's

High Convenience, Low Social Presence (HiCo-LoSo)

Bosak (2008); Malone (2018) Kroger; Stop \& Shop

Terdiman (2018)

Amazon Go Store

Ryan (2017)

DSW shoes, Walmart

Canada, Bee Hex

Joseph (2017); Gonzalez (2018) IKEA; Kate Spade

Ingram (2017)

Geissler Grocery

Ridden (2012); Datoo (2013) Renew

\section{Low Convenience, High Social Presence (LoCo-HiSo)}

Edelson (2014) Kate Spade

Rigby (2017) Quiz

Barker (2018) Schnucks

High Convenience, High Social Presence (HiCo-HiSo) Carman (2017); Sephora (2018) Sephora

Grosman (2017)

Rebecca Minkoff

Bandaranayake (2018)

Marriott \& Dominos

Grosman (2017)

Lowes
Scent machines that disperse company-linked scents throughout store.

Digital price tags at Amazon 4-Star Stores updated based on Amazon.com prices and display different prices for Prime members. At Fry's, digital price tags also feature video ads, coupons, and nutritional information; stores can instantly change prices and activate promotions to undercut competitors.

Self-checkout using mobile, handheld scanners that allow consumers to scan groceries as they shop, bag them instantly, and leave the store after paying at self-checkout lane; options to pay through the scanners will exist in future.

Grab and go options that require consumers to scan their smartphones upon entry; they can then grab items and walk out, without needing to check out, because AI and cameras capture what consumers purchase and charge their account.

3D printers

- DSW: mobile scanners capture up to 5000 data points and allow consumers to customize shoes at pop-up locations.

- Walmart Canada: consumers create and print their own Christmas ornaments.

- Bee Hex: start-up company uses a food printer to help consumers create pizzas in any shape.

Augmented reality

- Consumers upload pictures of their room and virtually place IKEA furniture in it to create a desired look.

- Consumers can create custom Kate Spade handbags using an in-store augmented reality display that senses which bag the consumer has picked up, then offers various options for the consumer to choose to express personality (e.g., straps, flaps, bag charms).

In-store kiosks list recipe ideas, deal promotions, and information; consumers can review the deals and recipes to find ones that meet their needs.

Digital communication recycling bins track unique identification numbers, recognize people as they pass by, and send them targeted advertisements. Stores might rely on the same tracking device in the future so that they can send consumers walking near the bin advertisements if a unique identification number appears.

Ceiling projection systems "Pick me up" signs on tables; when consumers can pick up and explore the products, they show social media images and styling pictures on the tables.

Scatter wall, or digital screens that showcase social media content, photos, and videos from the retailer's campaigns.

Embodied inventory/supply chain robots such as Tally that roam stores, assessing inventory levels; the robot has two blinking eyes on a digital screen to make it look friendly.

Social augmented reality that allows consumers to take pictures of themselves and then try on cosmetics and receive suggestions, both from the app and from friends with whom the consumers share the pictures on social media.

Smart mirrors in dressing rooms allow shoppers to adjust the lighting and contact sales associates to obtain other desired products. Consumers can also see the items they are trying on in different colors or accessorized with various items to create unique looks.

Disembodied robots such as Alexa can turn on lights or provide information in response to requests from Marriott hotel guests, or else allow consumers to order pizza from Domino's through a voice-activated assistant.

Embodied customer service robots such as LoweBot roam stores to allow consumers to interact with it and get answers to their questions. 
Fig. 2 Low convenience, low social presence (LoCo-LoSo) instore technologies

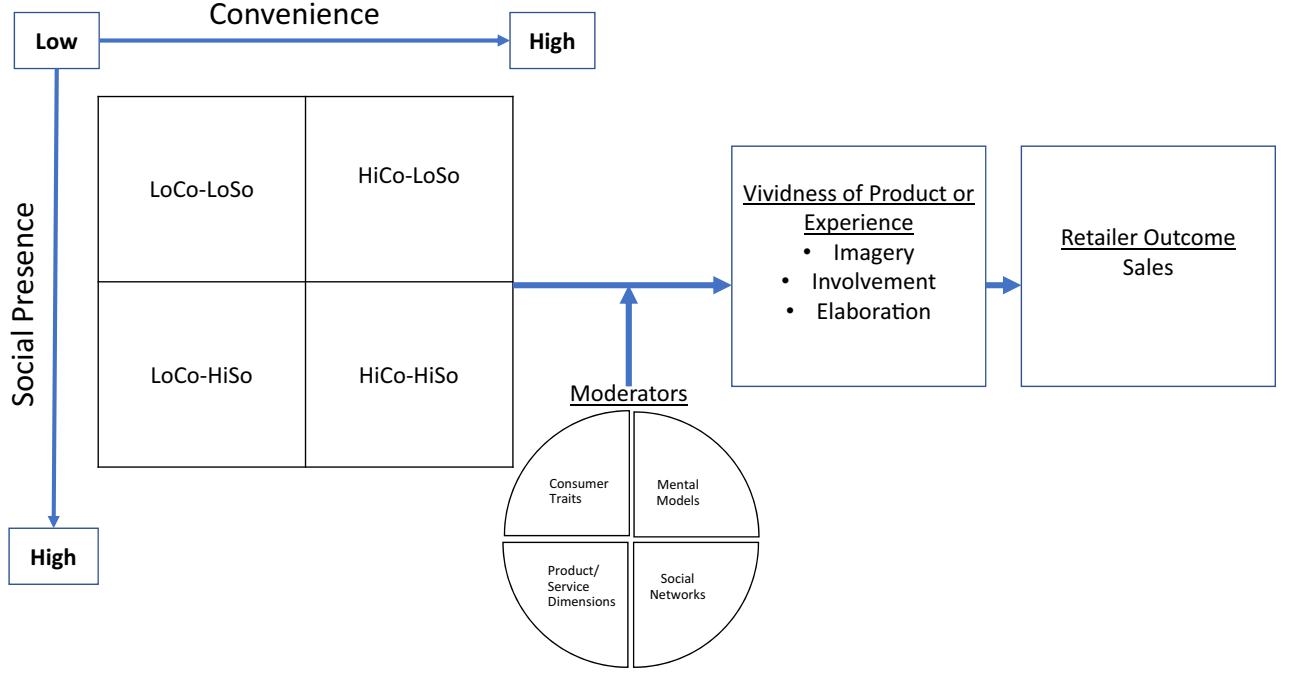

offers consumers' convenience benefits in terms of targeted promotions and readily available information, but little social presence. Below we touch on other examples of these new technologies.

Pushing self-checkout to a higher level of convenience, retailers like Amazon and Albertsons are experimenting with grab-and-go options. This technology is based on AI and cameras (Terdiman 2018). As shown in Fig. 3, Panel A, cameras can be installed in the ceiling that capture consumers as they select products. If consumers put the product back, even if on the wrong shelf, the cameras still capture this choice and adjust the shopping cart accordingly. These technologies offer great transaction convenience, because consumers can simply leave the store with their selections, without having to wait in line or pay with cash or credit card as the purchases are charged automatically to the consumer's account.

Augmented reality (AR) is now being used by retailers such as Kate Spade and IKEA to help consumers create their desired looks. When shoppers in a Kate Spade store touch a handbag, an AR display activates and encourages the shopper to personalize the bag. The personalized bag is then displayed to the shopper along with various styling options (Gonzalez 2018). IKEA allows consumers to upload pictures of a room to their IKEA place app (Joseph 2017) and then insert different furniture pieces to that picture to determine what looks best in the room (Joseph 2017). These technologies evoke access and benefit forms of convenience, but they have little social presence $^{2}$ (see Fig. 3, Panels B and C).

Artificial intelligence (AI) is now making narrowcasting possible. Narrowcasting entails the real-time dissemination of information enabled by artificial intelligence (AI) and digital displays. It differs from broadcasting in that specific information or messages are sent to specific stores (see Fig. 4).

\footnotetext{
${ }^{2}$ Although consumers can take screen shots of the virtual rooms in the IKEA app and share them with others, this social element is not widely promoted, so it appears the purpose of the app is primarily convenience oriented.
}

With this technology McDonalds is working to bring together big data and AI to make sure they have the right products on the digital menu boards to drive sales (Holmvik 2018). For example, if the temperature outside reaches a certain temperature, the menu board might make the displays of ice cream more prominent, but if temperatures drop, they may highlight coffee options. Because this information is targeted to specific stores, it should enhance customers' benefit convenience. According to our key informant, this narrowcasting technology is expected to lead to an average $1 \%-2 \%$ sales lift. While currently we categorize narrowcasting as being low on social presence, there are opportunities to highlight behaviors of other similar customers. This would then increase the social presence of this technology.

The LoCo-HiSo Quadrant comprises in-store technology infusions that are low on convenience, but high on social presence. These include embodied inventory robots, scatter walls of social media posts, and ceiling projection systems. Augmented reality and virtual reality are also being used in creative ways to enhance social presence. As will be expanded on below, each of these technologies evoke social presence in different ways. In addition, across all of them, they offer little convenience to the customer. To reinforce the point made earlier, being low on a convenience or social presence dimension does not diminish the potential importance to the retail firm. It may be that the benefit and value of the technology is more for the retailer (e.g., operational efficiency), than the consumer, as noted previously and exemplified by Schnuck's embodied inventory robot example below.

Embodied robots feature a human-like appearance or animated features. This can readily create a sense of social presence (van Doorn et al. 2017). At Schnucks grocery stores, embodied inventory robots roam stores, assessing inventory levels. Although not intended to interact with consumers, their design features two blinking "eyes" on a digital screen, to portray a friendly appearance (Barker 2018) (see Fig. 5, 
Fig. 3 High convenience, low social presence (HiCo-LoSo) instore technologies
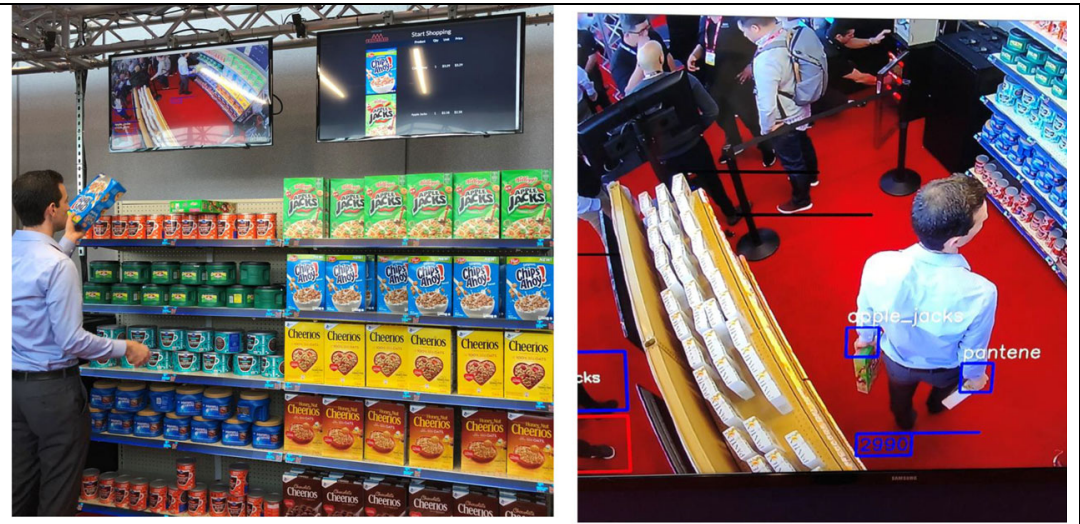

(a) AWM's Grab \& Go Retail Solution

Source: Pictures taken by the $2^{\text {nd }}$ author at NRF 2019 showroom floor.

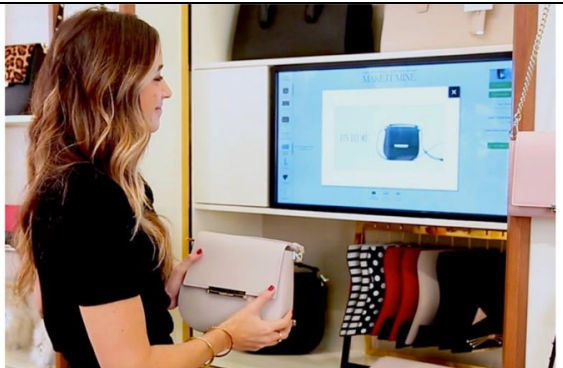

(b) Kate Spade Augmented Reality

Source: https://www.psfk.com/2018/09/kate-spade-store-ar-handbag-custom-design.html
Panel A). Although there is fewer convenience aspects for consumers, one potential benefit is that consumers will not be faced with stockouts. Greater convenience benefits are at the company level, in that, inventory robots reduce employee costs and stocking efficiencies.

Scatter walls and ceiling projection systems project social media posts and pictures that show diverse consumers using, enjoying, and styling the products available in stores (Edelson 2014). By projecting these images, retailers are fostering a sense of connection between customers as part of a worldwide network of brand customers. The ceiling projection system in Kate Spade stores beams "Pick me up" signs onto tables, encouraging consumers to interact physically with the products. When they do so, the system starts to project images from social media onto the same tables (see Fig. 5, Panel B). Although these technologies offer few convenience benefits to consumers, they encourage them to sense as if they are communing with others (Biocca and Harms 2002; Biocca and Nowak 2001; Heeter 1992).

Augmented reality is also being used to create high social presence. LEGO uses AR to merge physical and digital forms of playing (Buckley 2018). Children can build their designs using the physical LEGO blocks, add a photo of the design into a smartphone, and then enrich the play experience by
Fig. 4 Progression of broadcasting to AI enabled narrowcasting
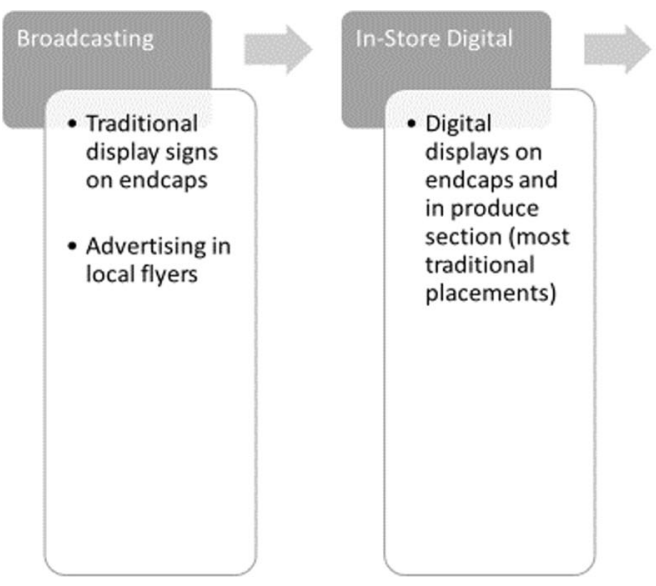

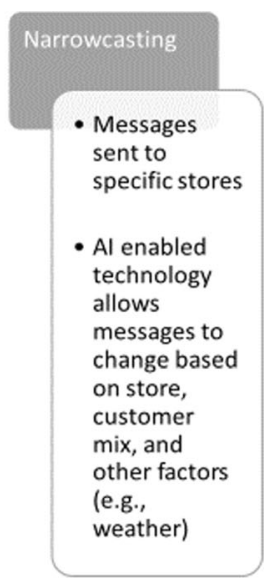


Fig. 5 Low convenience, high social presence (LoCo-HiSo) instore technologies

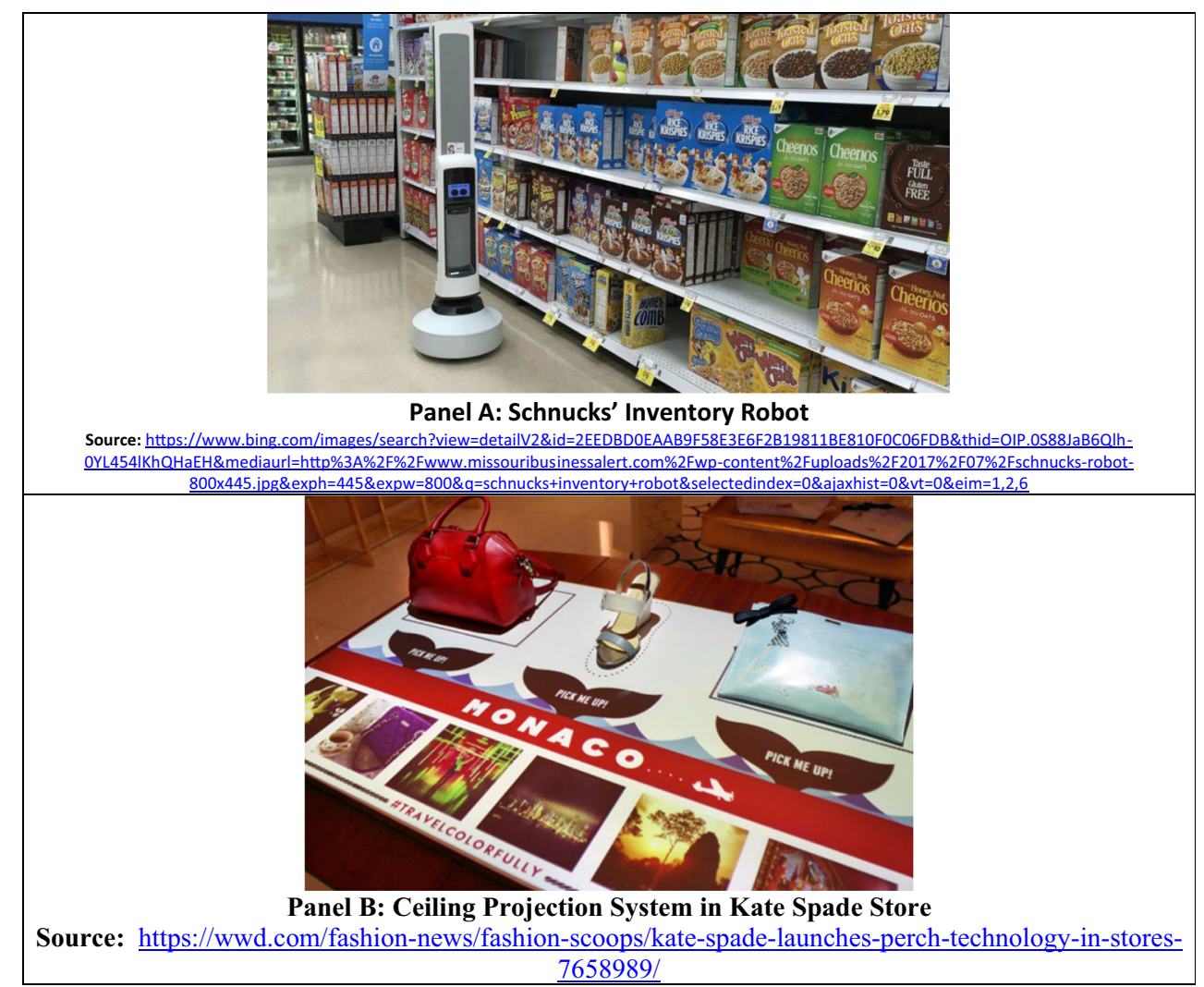

interacting with the design in an AR app. The experience prompts social presence by bringing the design to life, with characters superimposed over the structure they have built. This blend of physical designs and digital characters encourages a storyline that should increase engagement with LEGO products.

Finally, the HiCo-HiSo Quadrant technologies combine high convenience and high social presence. These technologies include augmented and virtual realities, consumer-facing robots (embodied and disembodied), click-and-flick smart windows, avatars, smart displays, as well as Hero, an omnichannel platform connector.

The AR technologies in this quadrant offer all the convenience benefits of those we described in the HiCo-LoSo quadrant, but also heighten social elements by enabling consumers to share the images they create with friends and family. For example, on Sephora's website, consumers can upload pictures of themselves and try different makeup looks, then save and share these looks with friends through social media platforms (Carman 2017; Sephora 2018).

Both social presence and convenience are possible in VR applications as well. Consider the virtual car showroom of Cadillac cars created by All Things Media (ATM) in partnership with Cadillac and the gaming software firm Unity. This technology was featured at the 2019 NFR Big Show. In this virtual showroom, consumers could customize Cadillacs, which appeared in 3D through the VR headsets (see Fig. 6,
Panel A) (Han 2017). The headsets provide visual connections, such that while consumers virtually explore the car, others can view their 3D experience simultaneously through monitors - either in the store or at home. They also support voice communications, such that the consumers can interact with other users, whether those users are in the store or at home (Bailey 2019). The consumer wearing the headset engages with others throughout the experience - a form of social presence that is unique to this VR application (ATM 2019).

Other VR technologies rely on storytelling to humanize the brand and create social presence. McCormick and Company uses VR to allow consumers to experience the McCormick flavor journey (Kemet 2019). Consumers scan product codes in a store, such as the one on a cinnamon container. This then prompts their smartphones to play related videos, such as stories of cinnamon tree fields in Saigon, cinnamon harvesting, and local farmers. Consumers can virtually walk through the cinnamon fields and watch its harvesting, which creates a human element to the spice and its production process (see Fig. 6, Panel B) (Kemet 2019). The videos also provide product information, establishing convenience benefits too.

Disembodied robots (e.g., don't have a human like appearance), such as Alexa or Siri, both enhance convenience by providing immediate information and action, but also instill a sense of social presence by enabling two-way communication flows. At select Marriott hotels, guests can ask Alexa for 


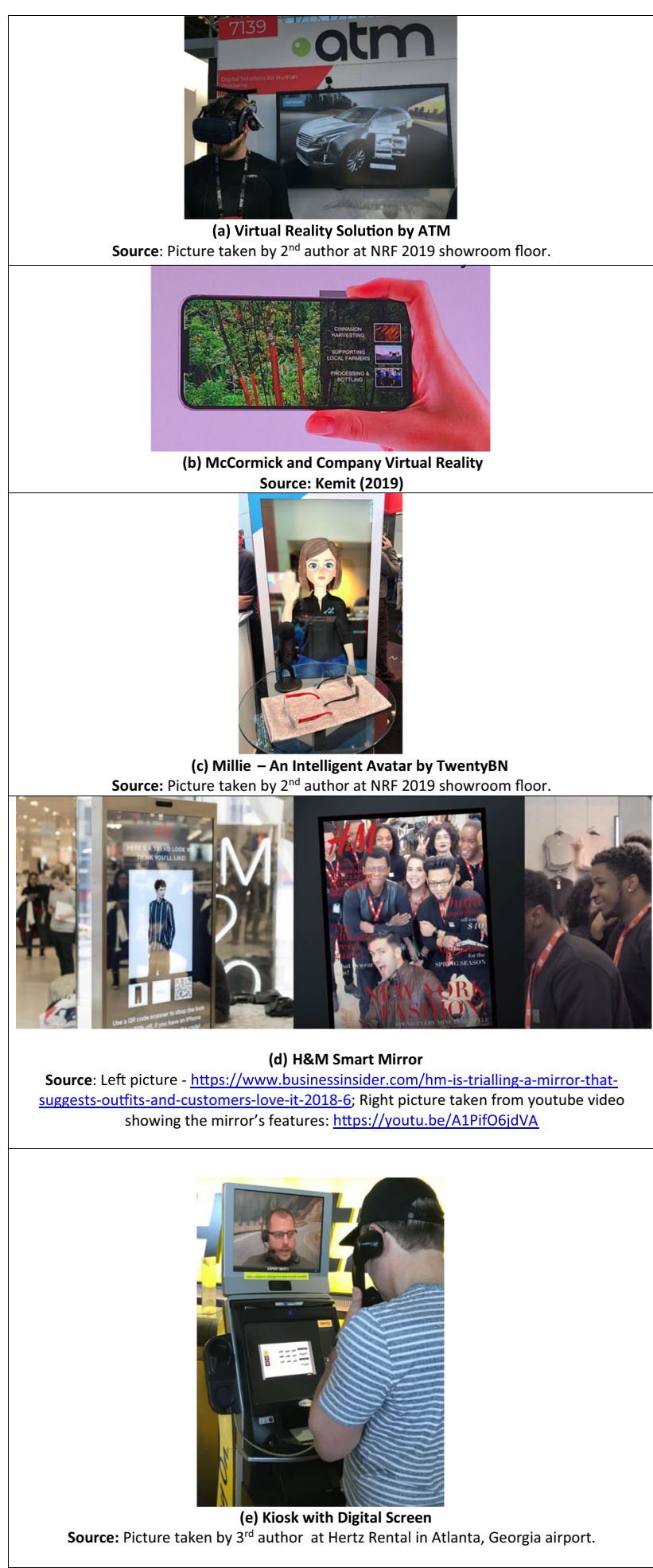

Fig. 6 High convenience, high social presence (HiCo-HiSo) in-store technologies

information, to turn on lights, and to order room service (Bandaranayake 2018). In homes, consumers can ask Alexa to tell them a joke or the weather.

Embodied robots present a human appearance which enhances social presence. In addition, they offer enhanced convenience in terms of information search, ordering, and other tasks for the customer. Lowe's in-store embodied robots roam stores, offering to assist consumers (Grosman 2017). The Mandarin Oriental in Las Vegas uses Pepper (an embodied robot) to support staff by greeting visitors, providing directions and answering property-specific questions. Pepper stands at four-feet and has large eyes, offers lifelike gestures, and even can use facial recognition technology to discern the gender, age, and even mood of the guest. Pepper can also tell jokes and pose for pictures (Walsh 2018).

Avatars can also be used to create high convenience and social presence. Consider Millie, an avatar that uses AI to engage consumers in conversation, functioning as a store greeter, navigator, personal stylist, or brand ambassador (see Fig. 6, Panel C). Millie encourages potential customers to try on sunglasses, then offers suggestions, compliments, and answers to their questions. Her social presence was demonstrable, through her appearance, interactivity, and mannerisms; her ability to answer questions also offered convenience benefits (TwentyBN 2019).

Smart windows are another new technology. Clas Ohlson stores are experimenting with windows that consumers can control with their smartphones (Esteka 2018; see Fig. $7^{3}$ ). Outside the store, a welcome window activates and displays a QR code when a consumer walks by it. It also displays instructions to scan the QR code to take control of the window display. Once the consumer does that, the shopper can control the window display with his/ her smartphone which functions like a remote control. As the consumer flicks their phones from right to left, it moves products across the screen. The products displayed on the window appear simultaneously on the consumers' smartphones, so they can make purchases easily. Similar display screens appear throughout the store. Beyond its appealing novelty, this technology comes to life and interacts with consumers (high social presence) and offers access, benefit, and transaction convenience.

Smart displays can also evoke a felt human presence. H\&M's smart mirror in Times Square, New York is not in a dressing room like most mirrors, but in a prominent location in the flagship store. Developed by Ombori and Microsoft, the mirror activates and starts to talk when consumers are standing near it; such activation helps draw consumers in and helps them overcome any hesitation engaging with it, according to one of the developers (Hassellof 2019). Once drawn in the mirror asks if you want to take a selfie or get fashion inspiration. For fashion inspiration looks, the mirror will ask a few additional questions to ensure useful looks are presented. QR codes are shown with presented styles (see Fig. 6, Panel $\mathrm{D}$, Left Side). If the selfie option is taken, the mirror will take a picture of the consumer and show the picture as a 
Fig. 7 Click and flick technology
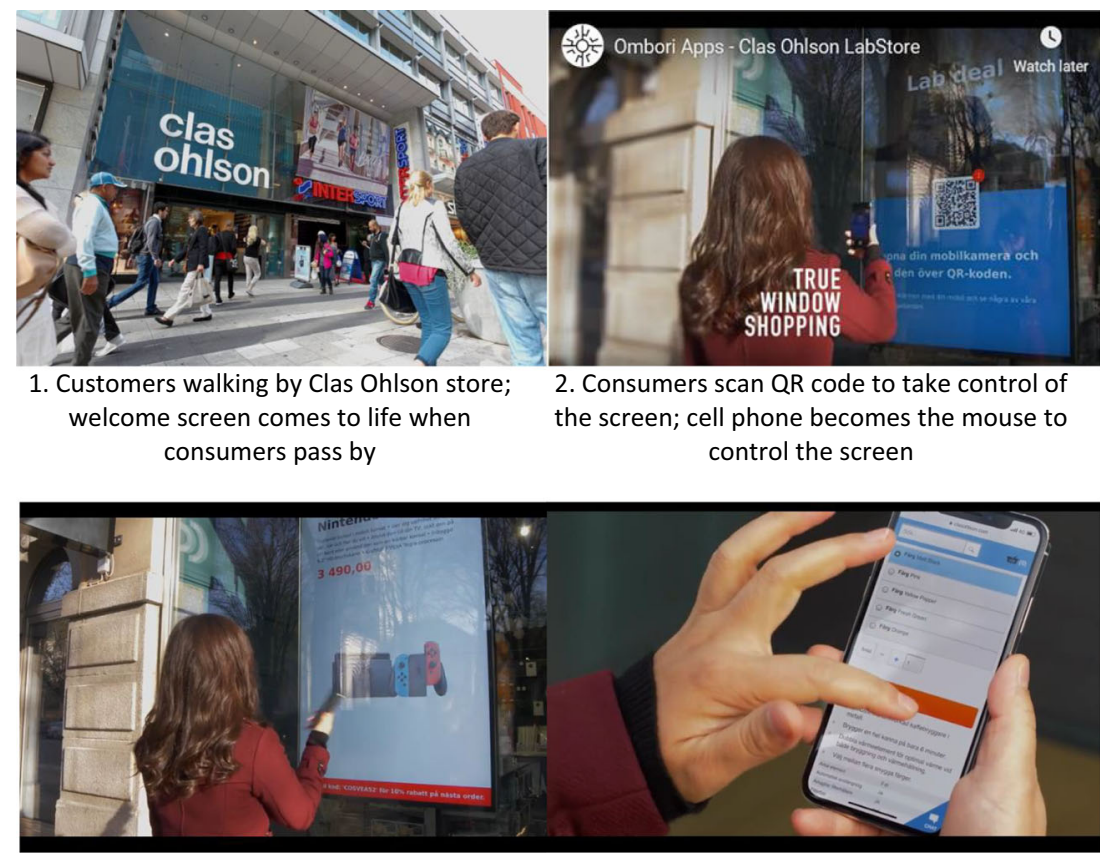

3. Consumers flick their cell phone in a right to left motion to swipe products across the screen
4. Products also show up on consumers' cell phones where they can place it in their basket and purchase it

Source: Pictures are from Online and Youtube Source.

cover of an H\&M magazine (see Fig. 6, Panel D, Ride Side). Consumers can then upload the fashion cover picture by scanning the QR code and share it on social media. According to Hassellof (2019) more than 100 consumers a day were taking a selfie with the mirror when it was first introduced and $86 \%$ of those taking a selfie also scanned QR codes - which helped redirect consumers into the e-commerce space. H\&M's smart mirror exhibits high levels of both social presence (i.e., mirror talks and interacts with consumers) and convenience (i.e., offers inspirational looks geared towards consumers' preferences with downloadable QR codes).

More traditional smart mirrors, such as those in dressing rooms, connect consumers with sales associates at greater distances (Grosman 2017). In addition, consumers also can access online inventory through the mirrors, change color options, and see styling suggestions. Thus, they enjoy convenience during the experience, while also sensing a social connection to the sales associates. In a similar manner, Hertz has begun implementing kiosks with digital screens at the top of the kiosk. The digital screen on top of the kiosk creates a "face-time" like call with a customer service agent who can help you rent your car. The customer service agent is located in a different location and simply face-times into the kiosk when there is a customer requiring assistance. The kiosk prints the necessary paper work and allows the customer to input information (see Fig. 6, Panel E). Thus, by streamlining the allocation of workers on a real-time basis, the company has been able to enhance convenience for customers and maintain social presence. This technology connects remote agents to a customer in a physical rental location.

On the flip side of this is technology which connects remote consumers to a physical retail store. The Hero omnichannel platform connects online shoppers to retail associates in physical stores. When a consumer shopping online types in a question, Hero geolocates them and sends a message to retail associates in the area, who respond to the question and communicates directly with the consumer. Unlike online chatbots or call centers, these sales associates are proximate to the customer (according to a customizable range), and their shared location helps establish a stronger social presence. The sales associate also can invite online customers to visit the store. According to Marc Hruschka, President of Luxury Strategy and Partnerships, the program reduces product return rates by $40 \%$, and stores achieve an $8 \%-10 \%$ lift in conversions (Hero 2019). Thus, the geolocation-based platform heightens the social presence of sales associates for online consumers while also providing them with a convenient way to gather information before making a purchase, whether online or after visiting the store. 


\section{Impacts of new and futuristic in-store technology infusion on retail outcomes: An organizing framework}

As described in our $2 \times 2$ typology, there are many new and futuristic technologies which retailers and service providers can infuse in their stores. The relevant question for retailers and service providers to ask, however, is: how will this technology impact either the customer experience or the backend operations of the store? In this paper we focus on the vividness of the customer experience, specifically, how vivid the product or shopping experience becomes as a result of in-store technology infusion (see more on vividness below) and how that ultimately influences sales. To better understand the impacts of in-store technology infusions on retail outcomes, we create an overall conceptual model (see Fig. 8). To develop this model, we draw from vividness theory (Nisbett and Ross 1980) to show imagery, involvement, and elaboration of the product or experience enhances sales. We also explore the impact of four moderating factors: consumer traits, mental models, product/service dimensions, and social networks. Each of these aspects is discussed below.

\section{In-store technology infusion and retail sales: The mediating role of vividness}

A key criterion to consider is whether the technology infusion enhances the vividness of the product or experience for customers. For example, by being in a Cadillac virtual showroom, the car comes to life in the eyes of the consumer. They can explore the car in ways they couldn't online. In addition, the store does not have to have that Cadillac physically in stock for the customer to experience it. With the ability to interact with others, it also enhances social presence and the reality that this product could actually be part of your life. People can visualize using the product, and the social presence further enhances that visualization.

Vividness can be defined as that which is temporally proximal, physically proximal, or emotionally appealing (Nisbett and Ross 1980). A vivid situation or product is one where a consumer's ability to visualize and imagine that situation/ product is enhanced (Nowlis et al. 2004; Shiv and Huber 2000). Heightened mental processing (Hoch and Loewenstein 1991) and involvement (Coyle and Thorson 2001; Li et al. 2001) are also characteristics of vivid situations, with such vividness ultimately influencing preferences. For example, Roggeveen et al. (2015) found that showing a product in a dynamic (versus static) visual format enhanced information vividness, which increased preference for the displayed product. Steuer (1995) also establishes that vividness can occur in the technology-mediated environments, such as virtual reality experiences, because the rich sensory information help consumers feel as if they are part of the environment.

While most of the technologies described above have some ability to enhance the vividness of a product, we suggest that those technologies in the HiCo-HiSo quadrant will lead to the most vivid experiences for consumers. Those technologies offer both high convenience and high social presence. These technologies grant consumers new options for exploring, shopping, and sensing the product or service experience. These high convenience benefits enable and encourage consumers to explore the product/situation in richer and deeper ways than they would have been able to otherwise. In addition, because of the high social presence those technologies offer, they will produce powerful feelings of being emotionally, physically, and temporally connected to products or the situation. This further brings the product and situation to life. Together the high levels of convenience and social presence attract consumers, making them more physically and temporally engaged as they interact with the technology to gain
Fig. 8 Conceptual model of instore technology infusion

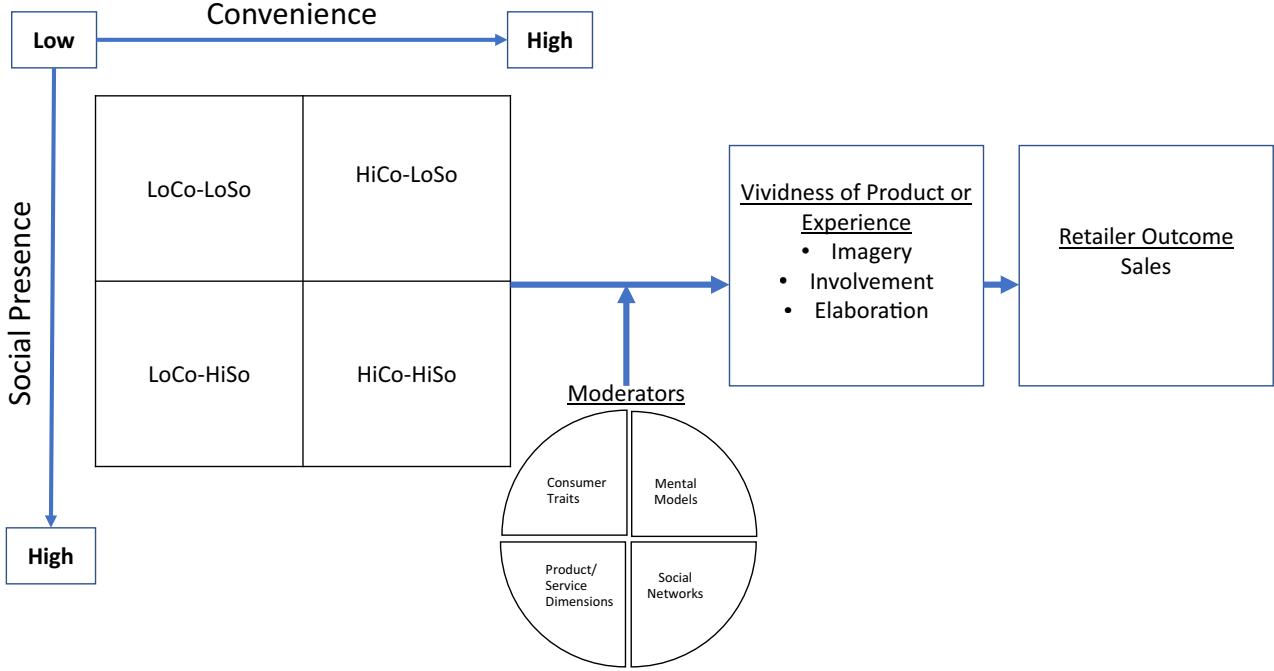


convenience benefits and more mentally connected through their sense of social presence.

Because such rich, dynamic stimuli enhance the vividness of the situation - to the extent that consumers will heighten their imagery of the product, involvement, and mental elaboration-we expect that technologies with high levels of convenience and social presence will help consumers perceive product and service benefits, stimulate their touching and trial, and increase preferences and purchase likelihood. Thus, we propose:

P1: In-store technology infusions that evoke high levels of convenience and social presence elicit higher desirable outcomes, such as sales, than the other three quadrants.

P2: Vividness perceptions mediate the effect of in-store technology infusions on retail outcomes, such that in-store technology infusions that evoke high levels of convenience and social presence elicit higher levels of (a) imagery, (b) involvement, and (c) elaboration than the other quadrants.

\section{Moderating effects}

Of course, the effectiveness of the technology in creating these vivid perceptions and enhancing sales, will depend on a multitude of other factors. In this next section, we discuss four potential moderating areas - consumer traits, product/service dimensions, mental models, and social networks. Each of these areas can have a multitude of underlying factors. For example, consumer traits can include technology readiness, gender, age, past experiences; product/service factors can include hedonic/utilitarian, pricing, degree of tangibility, usage occasion. For parsimony we focus on one example for each moderator.

Consumer traits Consumers' experiences with in-store technology infusion depend on a multitude of factors, including consumer traits and characteristics. This could include demographic factors such as age or gender or it may well depend on the consumers own technological readiness or the level of experience the consumer has with technology. We focus on technology readiness to illustrate its impact.

Technology readiness Parasuraman (2000) reflects a consumer's tendency to embrace, adopt, and use new technologies. The growing prevalence of consumer-facing technologies in retail stores likely is appreciated by some consumers, but others have negative reactions (Dabholkar 1996; Mick and Fournier 1998) that inhibit their use. In fact, in some situations, technology can function as a barrier to the customer experience (Giebelhausen et al. 2014). Shoppers who are technology ready are more likely to overlook negative aspects and embrace the opportunity to experience the technology infusion. This technology readiness is expected to make the consumer more open to the convenience benefits and the social presence, which will enhance the consumer's ability to vividly experience the product, which will in turn enhance sales. As a result, we expect technological readiness of the consumer to moderate the impact of the in-store technology infusion on sales. More formally:

P3: The positive effect of in-store technology infusions on vividness is stronger for consumers who exhibit higher (vs. lower) technology readiness.

Product/service dimensions One common way to classify products and services is based on whether they are more hedonic and utilitarian (e.g., Babin, Darden, and Griffin 1994; Roggeveen et al. 2015). Hedonic products and services are purchased for fun, enjoyment, and pleasure (Babin, Darden, and Griffin 1994; Childers et al. 2001); utilitarian ones are purchased for practical uses and are based on needs (Khan and Dhar 2004). Consumers evaluate products and experiences on both dimensions simultaneously, and any given purchase can have both utilitarian (e.g., gas mileage; cost of haircut) and hedonic (e.g., car design; trendy haircut) elements (Dhar and Wertenbroch 2000). Consumers tend to be less price sensitive toward purchases with more hedonic attributes, because they offer experiential aspects (Khan and Dhar 2004).

In a related manner, in-store technology infusions may be more useful with hedonic purchases. Hedonic products and services offer more experiential aspects (Khan and Dhar 2004) which is likely to make consumers more open to using technology infusions that further enhance that experience. The enjoyment attained from using products and services with more hedonic attributes encourages consumers to approach and explore those offerings, as well as the technology associated with it. As a result, they perceive the product and service imagery more clearly due to their physical proximity. In addition, as consumers increasingly look at, touch, and explore the product/service, with the help of the technology, they become more involved in the experience. The result is that consumers are expected to have more vivid experiences with the technologies for hedonic products and services than for utilitarian ones. In sum, we propose:

P4: The positive effect of in-store technology infusions on vividness is stronger for hedonic (versus utilitarian) products and services.

Mental models Mental models represent different ways consumers process information. In this section we consider imagery as a mode of processing. Imagery processing is a mental 
processing mode that evokes sensory experiences. In fact, all human senses can be stimulated by elaborate imagery (MacInnis and Price 1987). In addition, physiological responses can be evoked (e.g., galvanic skin responses, heart rates, and muscle reactions, Lang 1979). Imagery is a powerful way to process information, and research demonstrates that when imagery is primed, the outcomes mimic what would have occurred if consumers experienced the product first hand (Schlosser 2003).

Imagery-based processing also increases recall (Childers and Houston 1984), learning (Bower 1972), and purchase intentions (Gregory et al. 1982; Roggeveen et al. 2015). For example, Gregory et al. (1982) found that consumers who imagine the benefits of a service (versus simply hearing about them) are more likely to subscribe to the service; Roggeveen et al. (2015) also show that imagery can encourage choices of hedonic products, by heightening the vividness of their hedonic attributes. Based on this, we anticipate that high levels of imagery-based processing heighten sensory experiences, which then may amplify the effect of in-store technology infusions on the vividness of the experience. That is, the convenience benefits and the social presence of the technology will be felt more strongly, which should heighten consumers imagery, involvement, and elaboration of the product or experience (i.e., the vividness of the experience). More formally:

P5: The positive effect of in-store technology infusions on vividness is stronger for consumers who process information in a higher (vs. lower) imagery mode.

Social networks The last area of moderators we discuss in this paper are social networks. Humans are social creatures, embedded in networks of friends, colleagues, and acquaintances (Granovetter 1985). Members of these networks transfer information and this information can influence a shopping situation. Therefore, we discuss one variable that is frequently used to describe social networks - tie strength — as a moderator in our framework.

Tie strength Being a member of a network provides an individual with a wealth of information. Because network members share their unique knowledge bases and grant one another access to information that otherwise would not be readily available (Granovetter 1983), it provides an individual in that network information that people outside of the network may not know. Via information sharing, networks members provide and receive support to deal with information uncertainty (Krackhardt 1992) which helps them understand new situations.

Interpersonal ties in a social network are the connections that allow for the transfer of information. Ties vary in strength, from weak to strong. For the specific context in which consumers' social networks influence in-store shopping behaviors, we focus on positive ties, through which information gets transferred. Strong ties refer to close friendships; weak ties are represented by acquaintances (Granovetter 2005). Depending on the situation, ties of different strengths may be optimal for information transfers. Weak ties are best for transferring novel information, because acquaintances are less like the focal consumer, such that they interact in different social networks, leading to less overlap in knowledge bases. In turn, these weak ties are more likely to transfer novel and innovative information (Burt 1992; Granovetter 2005). Strong ties, especially those built on a history of interactions, instead establish emotional intimacy and trust that represent forms of support when consumers face uncertainty (Krackhardt 1992).

Consumers encountering innovative in-store technologies for the first time might be initially apprehensive to touch, explore, and engage with them. Since consumers with stronger ties have heightened levels of trust in information transferred (Krackhardt 1992), positive information from strong ties about in-store technologies could alter engagement and immersion with them. This information does not need to be transferred when in the shopping situation, but could have occurred days, weeks or month prior. For example, over lunch a friend might enthusiastically recount making a purse in a Kate Spade store and detail the augmented reality technology that assisted her. If such information about the technology is recalled (or even vaguely remembered) when in the store at a later date it should encourage more immersion in the experience, even if there is still uncertainty in the situation, since it came from a strong tie where trust in the information is high (Krackhardt 1992). This immersion is expected to mentality strengthen the effect of in-store technology infusions on vividness. That is, when trusted information is transferred about instore technologies it will encourage enhanced engagement and immersion in the technology and experience, and heighten the sensory experience (imagery, involvement, and elaboration) of the technology infusion.

P6: The positive effect of in-store technology infusions on vividness is stronger for consumers who have stronger (versus weaker) ties.

\section{Future research directions and conclusion}

Retail technology (and related analytics) has continually been a game changer (Bradlow et al. 2017; Grewal, Roggeveen, and Nordfält 2017; Inman and Nikolova 2017). In this paper, we highlighted the role of new and future in-store technologies. This paper introduced a $2 \times 2$ typology of different innovative technologies focusing on their level of convenience and 
social presence for the consumer. Convenience signifies the time and effort savings the technology provides consumers when buying or using a product or a service (Berry et al. 2002). Social presence refers to the degree to which the technology causes consumers to sense that they are in the presence of others (van Doorn et al. 2017). Importantly, social presence does not mean that another person must be physically present. Instead social presence may be felt with interactions with the machine itself (e.g., robots) (Heerink et al. 2010; van Doorn et al. 2017), human connections supported by the technology (Zhu et al. 2010) (e.g., social media posts), or technology that humanizes the brand (Schroll et al. 2018). It is important to note that although we present the quadrants as high and low levels of convenience and social presence, in reality each of these dimensions vary on a continuum. In addition, certain technologies may fall into multiple quadrants as a function of how the retailer or service provider is using the technology.

The paper then offers a series of propositions based on the idea that convenience and social presence can trigger vividness. Vividness theory (Nisbett and Ross 1980) suggests that when an outcome (e.g., a purchase) is more vivid, due to enhanced consumer involvement, imagery, and elaboration, retailer and service provider sales are ultimately enhanced.

Finally, the paper then focuses on four moderating areasconsumer traits, product/service dimensions, mental models and social networks - to understand how they might impact the vividness experienced via the technology. This is in no way an exhaustive list of possible moderators. Both our $2 \times$ 2 typology and the propositions evoke questions for continued research to address.

From a practical standpoint, we recognize that retailers and service providers inherently confront limited resources. As a result, they must prioritize their investments in in-store technologies. Where should they make those investments to achieve the greatest sales lift? The obvious answer is to infuse the technologies in the high convenience, high social presence (HiCo-HiSo) quadrant as this quadrant offers the richest opportunities to enhance vividness of the product or experience and ultimately enhance sales. There are several ways to reach more in the HiCo-HiSo quadrant. One way is to enhance technologies in the HiCo-LoSo quadrant with more social presence (e.g., adding animated faces to self-scanners). Another way is to make the technologies in the LoCo-HiSo quadrant more convenient (e.g., scatter walls and ceiling projection systems that provide customer reviews).

As research continues in in-store technology infusion, it is important to consider how tactile simulation impacts the felt vividness and subsequent sales. Research on tactile stimulation indicates the positive benefits of touch (Grohmann et al. 2007; Peck and Childers 2006; Spence et al. 2014). As technology is evolving it is possible to move consumers physically away from the touch-based display screens (e.g., via the "click-and-flick" smart window technology) or embed them in a virtual world where an avatar is 'touching' the product for them. What impact will that have on felt vividness and sales? Additional research should also investigate whether the novelty of the technology can balance out the potential limitations it imposes. A related line of research might examine moderating factors which would impact whether certain products sell better with click-and-flick or touchscreen displays.

We propose a 2 X 2 typology with the dimensions of convenience and social presence, however, other dimensions could be explored as they relate to our proposed typology, such as how the technology allows or threatens identity expression (Mende et al. 2019). Identities are mental representations for how we see ourselves (Stryker and Burke 2000). Triggered identities can drive our behaviors (Oyserman 2009; Reed et al., 2012); therefore, the degree to which technology infusions allow consumers to represent their individuality, sense of self, personality, etc. could be explored in the future as an extension of our typology. Another dimension might be the stage of the customer journey (Hamilton and Price 2019; Lemon and Verhoef 2016). Schamp, Heitmann, and Katzenstein (2019) showed that consumer receptivity to ethical attributes varied based on customer journey stage; perhaps receptivity to convenience and social benefits are influenced by the stage of the customer journey also.

Based on existing research we assume consumers, in general, have a strong desire for social presence (Donald 1991; Granovetter 1985); however, this is not always going to be true in every situation. The presence of others could impact your privacy (Esmark and Noble 2016; Esmark, Noble, Breazeale 2017), therefore future research should examine the potential dark side of social presence. Similarly, we examine the positive aspects of convenience, yet there might be a point where too much convenience becomes counter-productive. For example, grab and go self-checkouts afford convenience, but little social presence. What if all futuristic in-store technology infusions became so convenient, without any social elements? Would this be beneficial or harmful to society? Mende and Noble (2019) speak about a possible future where consumers crave human-to-human contact because technology becomes so efficient and effective at replacing frontline employees. In addition to Mende and Noble (2019) several recent articles speak to the evolving nature of the retail frontline (Arnold et al. 2019; Heller et al. 2019; Holmqvist et al. 2019; Hughes et al. 2019; Singh, Arnold, Brady and Brown 2019); the technologies noted in our typology are further evidence of this evolving retail landscape. Strategic introductions of technologies in our $2 \times 2$ typology offer ways for retailers and service providers to enhance the customer experience, and be competitive, in this rapidly changing environment.

We explore vividness of the product or experience as the mediator in our conceptual model, however there are other mediators that could also be explored. Some technologies 
Table 2 Future research questions

In-Store Technology and Convenience, Social Presence and Customer Experiences

- Does stage of the consumer journey influence receptivity to the convenience and social presence dimensions and the respective technologies identified in the four quadrants?

-We have proposed linear effects for the dimensions of social presence and convenience implicit in these new in-store technologies on customer experiences and behavioral outcomes. However, are there also likely to be non-linear effects? Can an in-store technology be too convenient, and result in lower sales?

- Vividness was proposed as one possible mediator - many technologies in the HiCo-HiSo quadrant enhance vividness by enabling consumers to be co-producers of the experience. Could felt control in the co-production of the experience be an additional mediator?

- What other dimensions besides convenience and social presence, such as identity expression, could help categorize new and emerging technologies?

\section{In-Store Technology and Touch}

- Does our existing knowledge about touch eliciting ownership feelings and purchase intentions transfer to augmented and virtual reality settings?

- Does an embodied robot touching a product contaminate it less than human touch?

- Given many positive aspects of touch, what is the impact of moving consumers physically away from traditional touch-based display screens to technologies like 'click-and-flick' smart windows, where consumers are further removed from touching anything in the store?

\section{In-Store Technology and FLEs}

- Under what circumstances would consumers prefer engagement with technology infusion to engagement with frontline employees (FLEs)?

- Can humanoid robots/avatars instill the same social presence feelings as FLEs? Under what conditions might this be possible?

-When is a geolocation system for connecting remote FLEs to customers most helpful?

- Do consumers form relationships with in-store technologies, such as embodied robots and avatars, like they do with FLEs?

Negative Effects of In-Store Technology

- Technologies inevitably fail at some point in time. Would failure of in-stores technologies in the HiCo-HiSo quadrant negatively impact customers' experiences more than failures of FLEs?

- Does size of the retailer or service provider matter for the effectiveness of the in-store technology? For example, perhaps in-store technologies detract from personal relationship in smaller retailers. If so, HiCo-HiSo technologies would be best suited for larger retailers.

- What are the dark side effects of in-store technologies? What would be the societal impact if many technologies became highly convenient? How would the lack of social elements influence societal quality of life?

- Technologies can distract consumers. Under what conditions would $\mathrm{HiCo}-\mathrm{HiSo}$ technologies distract consumers from the experience and decrease sales?

enable consumers to be co-producers of their experience. Such co-production can give consumers control over the situation with varying outcomes (Bendapudi and Leone 2003; Esmark, Noble, Bell, and Griffith 2016), therefore future extensions of the model could explore elements of felt control. Technology has also been shown to be a distraction in some situations (Grewal et al. 2018), therefore distraction could also be another possible mediator for future research.
We present future research ideas in Table 2. These ideas are organized by the effects of in-store technology on: (1) convenience, social presence, and customer experiences; (2) role of touch; (3) on relationships with FLEs; and (4) negative or dark-side effects. In addition to summarizing the above ideas, we outline additional research questions related to the emerging and futuristic technologies outlined in the HiCo-HiSo quadrant, as these were proposed to offer the richest opportunities to enhance vividness of the product or experience, and ultimately sales. We hope the article and these ideas stimulate future research in this area of the role of in-store technology.

Open Access This article is distributed under the terms of the Creative Commons Attribution 4.0 International License (http:// creativecommons.org/licenses/by/4.0/), which permits unrestricted use, distribution, and reproduction in any medium, provided you give appropriate credit to the original author(s) and the source, provide a link to the Creative Commons license, and indicate if changes were made.

\section{References}

Arnold, T., Grewal, D., Motyka, S., Kim, N., Sharma, A., \& Srivastava, R. (2019). Store manager-store performance relationship: A research note. Journal of Retailing, 95(2), 144-155.

ATM. (2019). Personal communication with Stephen Jackett, chief operating officer at all things media (ATM) at the National Retail Federation Innovation lab. January, 14, 2019.

AWM Smart Shelf (2019). Retail solutions: World's most innovative smart shelf technology. Retrieved February 11, 2019 from https:// smartshelf.com/retail_solutions.html

Babin, B. J., Darden, W. R., \& Griffin, M. (1994). Work and/or fun: Measuring hedonic and utilitarian shopping value. Journal of Consumer Research, 20, 644-656.

Bailey, R. (2019). ATM on Unity. Retrieved February 11, 2019 from $\mathrm{http}$ //allthingsmedia.com/news/moredetails/341

Bandaranayake, N. (2018). How voice tech is shaping shopper behavior. Retrieved February 11, 2019 from https://nrf.com/blog/how-voicetech-is-shaping-shopper-behavior

Barker, J. (2018). More robots to hit the aisles at Schnucks grocery stores in St. Louis area. Retrieved February 11, 2019 from https://www. stltoday.com/business/local/more-robots-to-hit-the-aisles-atschnucks-grocery-stores/article_31d25228-3bf0-55d4-a2c3c44fa8fe90ae.html

Bendapudi, N., \& Leone, R. P. (2003). Psychological implications of customer participation in co-production. Journal of Marketing, 67, $14-28$.

Berry, L. L., Seiders, K., \& Grewal, D. (2002). Understanding service convenience. Journal of Marketing, 66, 1-17.

Biocca, F., \& Harms, C. (2002). Defining and measuring social presence: Contribution to the networked minds theory and measure. Proceedings of PRESENCE, 1-36.

Biocca, F., \& Nowak, K. (2001). Plugging your body into the telecommunication system: Mediated embodiment, media interfaces, and social virtual environments. In C. Lin \& D. Atkin (Eds.), Communication technology and society (pp. 407-447). Waverly Hill: Hampton Press.

Bosak, C. (2008). Shop \& Shop scans its way into future. Retrieved February 11, 2019 from https://www.thehour.com/business/article/ Stop-Shop-scans-its-way-into-future-8277700.php 
Bower, G. (1972). Mental imagery and associative learning. In L. Gregg (Ed.), Cognition in Learning and Memory. New York: Wiley.

Bradlow, E. T., Gangwar, M., Kopalle, P., \& Voleti, S. (2017). The role of big data and predictive analytics in retailing. Journal of Retailing, 93, 79-95.

Buckley, J. (2018). Senior director. PTC, Phone Interview, December, 18, 2018.

Burt, R. (1992). Structural holes: The social structure of competition. Cambridge: Harvard University Press.

Carman, A. (2017). Sephora's latest app update lets you try virtual makeup on at home with AR. Retrieved February 11, 2019 from https:// www.theverge.com/2017/3/16/14946086/sephora-virtual-assistantios-app-update-ar-makeup

Childers, T. L., \& Houston, M. J. (1984). Conditions for a picturesuperiority effect on consumer memory. Journal of Consumer Research, 11, 643-654.

Childers, T. L., Carr, C. L., Peck, J., \& Carson, S. (2001). Hedonic and utilitarian motivations for online retail shopping behavior. Journal of Retailing, 77, 511-535.

Copeland, M. T. (1923). Relation of consumers' buying habits to marketing methods. Harvard Business Review, I, 282-289.

Coyle, J. R., \& Thorson, E. (2001). The effects of progressive levels of interactivity and vividness in web marketing sites. Journal of Advertising, 30, 65-77.

Dabholkar, P. A. (1996). Consumer evaluations of new technology-based self-service options: An investigation of alternative models of service quality. International Journal of Research in Marketing, 13, $29-51$.

Dahl, D. W., Manchanda, R. V., \& Argo, J. J. (2001). Embarrassment in consumer purchase: The roles of social presence and purchase familiarity. Journal of Consumer Research, 28, 473-481.

Danziger, P.N. (2017). Retail apocalypse: A look at what comes next and it isn't pretty. Retrieved February 11, 2019 from https://www.forbes. com/sites/pamdanziger/2017/07/13/retail-apocalypse-what-comesnext/\#46fb555c23d4

Datoo, S. (2013). This recycling bin is following you. Retrieved February 11, 2019 from https://qz.com/112873/this-recycling-bin-isfollowing-you/

Davis, F. D. (1989). Perceived usefulness, perceived ease of use, and user acceptance of information technology. MIS Quarterly, 13, 319-340.

Dhar, R., \& Wertenbroch, K. (2000). Consumer choice between hedonic and utilitarian goods. Journal of Marketing Research, 37, 60-71.

Donald, M. (1991). Origins of the modern mind: Three stages in the evolution of culture and cognition. Boston: Harvard University Press.

Dua, T. (2015). The North Face brings virtual reality to retail. Retrieved February 11, 2019 from https://digiday.com/marketing/north-facebrings-virtual-reality-retail/

Edelson, S. (2014). Perch, an interactive display system, seamlessly integrates rich media content into the in-store shopping experience. Retrieved February 11, 2019 from https://wwd.com/fashion-news/ fashion-scoops/kate-spade-launches-perch-technology-in-stores7658989/

Esmark, C. \& Noble, S.M. (2016). Your in-store customers want more privacy, Harvard Business Review (Digital Articles, pp. 2-4) https:// hbr.org/2016/12/your-in-store-customers-want-more-privacy. Accessed 1 Aug 2019

Esmark, C., Noble, S. N., Bell, J., \& Griffith, D. (2016). The effects of behavioral, cognitive, and decisional control in co-production service experiences. Marketing Letters, 27, 423-436.

Esmark, C., Noble, S. M., \& Breazeale, M. (2017). I'll be watching you: Shoppers' reactions to perceptions of being watched by employees. Journal of Retailing, 93, 336-349.

Esteka, V. (2018). Key account manager, Clas Ohlson, Phone Interview, December 13, 2018.
Giebelhausen, M., Robinson, S. G., Sirianni, N., \& Brady, M. (2014). Touch vs. tech: When technology functions as a barrier or a benefit to service encounters. Journal of Marketing, 78, 113-124.

Gonzalez, R. (2018). Kate Spade shoppers can customize their handbags in AR. Retrieved February 11, 2019 from https://www.psfk.com/ 2018/09/kate-spade-store-ar-handbag-custom-design.html

Granovetter, M. (1983). The strength of weak ties: A network theory revisited. Sociological Theory, 1, 201-233.

Granovetter, M. (1985). Economic action and social structure: The problem of embeddedness. American Journal of Sociology, 91, 481-510.

Granovetter, M. (2005). The impact of social structure on economic outcomes. Journal of Economic Perspectives, 19, 33-50.

Gregory, W. L., Cialdini, R. B., \& Carpenter, K. M. (1982). Self-relevant scenarios as mediators of likelihood estimates and compliance: Does imagining make it so? Journal of Personality and Social Psychology, 43, 89-99.

Grewal, D., Roggeveen, A. L., \& Nordfält, J. (2017). The future of retailing. Journal of Retailing, 93, 1-6.

Grewal, D., Ahlbom, C. P., Beitelspacher, L., Noble, S. M., \& Nordfält, J. (2018). In-store mobile phone use and customer shopping behavior: Evidence from the field. Journal of Marketing, 82, 102-126.

Grohmann, B., Spangenberg, E. R., \& Sprott, D. E. (2007). The influence of tactile input on the evaluation of retail product offerings. Journal of Retailing, 83, 283-294.

Grosman, L. (2017). The future of retail: How we'll be shopping in 10 Years. Retrieved February 11, 2019 from https://www.forbes.com/ sites/forbescommunicationscouncil/2017/06/20/the-future-of-retailhow-well-be-shopping-in-10-years/\#21188bbe58a6.

Hamilton, R., \& Price, L. L. (2019). Consumer journeys: Developing consumer-based strategy. Journal of the Academy of Marketing Science, 47, 187-191.

Han, G. (2017). Cadillac brings VR showrooms ever closer to reality. Retrieved February 11, 2019 from https://design-milk.com/ cadillac-virtual-reality/

Hassellof, A. (2019). CEO, Ombori group, Phone Interview, January 24, 2019.

Heerink, M., Kröse, B., Evers, V., \& Wielinga, B. (2010). Relating conversational expressiveness to social presence and acceptance of an assistive social robot. Virtual Reality, 14, 77-84.

Heeter, C. (1992). Being there: The subjective experience of presence. Presence, 1, 262-271.

Heller, J., Chylinski, M., Ruyter, K., Mahr, D., Debbie, I., \& Keeling, D. I. (2019). Let me imagine that for you: Transforming the retail frontline through augmenting customer mental imagery ability. Journal of Retailing, 95(2), 94-114.

Hero (2019). Personal communication with Marc Hruschka, President of Luxury Strategy \& Partnerships for Hero, at the National Retail Federation Innovation Lab, January 14, 2019.

Hoch, S. J., \& Loewenstein, G. F. (1991). Time-inconsistent preferences and consumer self-control. Journal of Consumer Research, 17, 492507.

Holmqvist, J., Vaerenbergh, Y. V., Lunardo, R., \& Dahlén, M. (2019). The language backfire effect: How frontline employees decrease customer satisfaction through language use. Journal of Retailing, 95(2), 115-129.

Holmvik, F. (2018). Retail management consultant, AB Processverkstad 17. Phone Interview, November, 29, 2018.

Hughes, D. E., Richards, K. A., Calantone, R., Baldus, B., \& Spreng, R. A. (2019). Driving in-role and extra-role brand performance among retail frontline salespeople: Antecedents and the moderating role of customer orientation. Journal of Retailing, 95(2), 130-143.

Hyder, S. (2014). Here's what you need to know about millennials. Retrieved February 11, 2019 from https:/www.forbes.com/sites/ shamahyder/2014/03/04/here-is-what-you-need-to-know-aboutmillennials/\#392c8494311d 
Ingram, B. (2017). Kiosks continue to get innovative. Retrieved February 11, 2019 from https://progressivegrocer.com/kiosks-continue-getinnovative

Inman, J. J., \& Nikolova, H. (2017). Shopper-facing retail technology: A retailer adoption decision framework incorporating shopper attitudes and privacy concerns. Journal of Retailing, 93, 7-28.

Joseph, S. (2017). How IKEA is using augmented reality. Retrieved February 11, 2019 from https://digiday.com/marketing/ikea-usingaugmented-reality/

Kemet, A. (2019). Igniting emotions through AR and VR. Session at the National Retail Federation's Big Show, New York City, January 15.

Khan, U., \& Dhar, R. (2004). A behavioral decision theoretic perspective on hedonic and utilitarian choice. In S. a. M. Ratneswhar, D. G. (Eds.), Inside consumption: Frontiers of research on consumer motives goals, and desires (pp. 144-165). London: Routledge.

Krackhardt, D. (1992). The strength of strong ties: The importance of philos in organizations. In N. Nohria \& R. Eccles (Eds.), Networks and organizations (pp. 216-239). Cambridge: Harvard Business School Press.

Krishna, A. (2012). An integrative review of sensory marketing: Engaging the senses to affect perception, judgment and behavior. Journal of Consumer Psychology, 22, 332-351.

Lang, P. J. (1979). A bio-informational theory of emotional imagery. Psychophysiology, 16, 495-512.

Lemon, K. N., \& Verhoef, P. C. (2016). Understanding customer experience throughout the customer journey. Journal of Marketing, 80, 69-96.

Li, H., Daugherty, T., \& Biocca, F. (2001). Characteristics of virtual experience in electronic commerce: A protocol analysis. Journal of Interactive Marketing, 15, 13-20.

MacInnis, D. J., \& Price, L. L. (1987). The role of imagery in information processing: Review and extensions. Journal of Consumer Research, 13, 473-491.

Malone, J.D. (2018). Kroger's 'scan, bag, go' trims grocery-shopping time, wins fans. Retrieved February 11, 2019 from https://www. dispatch.com/news/20180322/krogers-scan-bag-go-trims-groceryshopping-time-wins-fans

Mende, M., \& Noble, S. M. (2019). Retail apocalypse or Golden opportunity for retail frontline management? Journal of Retailing, 95, 84 89.

Mende, M., Scott, M. L., van Doorn, J., Grewal, D., \& Shanks, I. (2019). Service robots rising: How humanoid robots influence service experiences and elicit compensatory consumer responses. Journal of Marketing Research, 56(August), 535-556.

Mick, D. G., \& Fournier, S. (1998). Paradoxes of technology: Consumer cognizance, emotions, and coping strategies. Journal of Consumer Research, 25, 123-143.

Nisbett, R. E., \& Ross, L. (1980). Human inference: Strategies and shortcomings of social judgment. Englewood Cliffs: Prentice Hall.

Nowlis, S., Mandel, N., \& McCabe, D. B. (2004). The effect of a delay between choice and consumption on consumption enjoyment. Journal of Consumer Research, 31, 502-510.

Oyserman, D. (2009). Identity-based motivation: Implications for actionreadiness, procedural readiness, and consumer behavior. Journal of Consumer Psychology, 19, 250-260.

Parasuraman, A. (2000). Technology readiness index (TRI): A multipleitem scale to measure readiness to embrace new technologies. Journal of Service Research, 2, 307-320.

Peck, J., \& Childers, T. L. (2006). If I touch it I have to have it: Individual and environmental influences on impulse purchasing. Journal of Business Research, 59, 765-769.

Pew Research Center (2010). Millennials: Confident. Connected. Open to change. Retrieved February 11, 2019 from http://www. pewsocialtrends.org/2010/02/24/millennials-confident-connectedopen-to-change/
Redmond, A. (2017). How millennials signal personal identity through brand preference. Retrieved February 11, 2019 from https://www. entrepreneur.com/article/287794

Reed, A. I. I., Forehand, M. R., Puntoni, S., \& Warlop, L. (2012). Identity-based consumer behavior. International Journal of Research in Marketing, 29, 310-321.

Ridden, P. (2012). Digital communication pods double as recycling bins to clean up London's streets. Retrieved February 11, 2019 from https://newatlas.com/renew-recycle-bin/21525/

Rigby, C. (2017). Quiz brings digital into Westfield Stratford store. Retrieved February 11, 2019 from https://internetretailing.net/ themes/themes/quiz-brings-digital-into-westfield-stratford-store15243

Roggeveen, A. L., Grewal, D., Townsend, C., \& Krishnan, R. (2015). The impact of dynamic presentation format on consumer preferences for hedonic products and services. Journal of Marketing, 79, 34-49.

Rubin, F. (2018). New Amazon 4-star store makes high ratings a selling point. Retrieved February 11, 2019 from https://www.cnet.com/ news/a-visit-to-the-new-amazon-4-star-store-store-in-manhattan/

Ryan, T. (2017). How will 3-D printing take hold at retail? Retrieved February 11, 2019 from https://www.retailwire.com/discussion/ how-will-3-d-printing-take-hold-at-retail/

Schamp, C., Heitmann, M., \& Katzenstein, R. (2019). Consideration of ethical attributes along the consumer decision-making journey. Journal of the Academy of Marketing Science, 47, 328-348.

Schlosser, A. E. (2003). Experiencing products in the virtual world: The role of goal and imagery in influencing attitudes versus purchase intentions. Journal of Consumer Research, 30, 184-198.

Schroll, R., Schnurr, B., \& Grewal, D. (2018). Humanizing products with handwritten typefaces. Journal of Consumer Research, 45(4), 648-672.

Seiders, K., Voss, G. B., Grewal, D., \& Godfrey, A. L. (2005). Do satisfied customers buy more? Examining moderating influences in a retailing context. Journal of Marketing, 69, 26-43.

Sephora (2018). Retrieved February 11, 2019 from https:// sephoravirtualartist.com/landing_5.0.php?country=US\&lang= en $\& \mathrm{x}=\&$ skintone $=\&$ currentModel

Shiv, B., \& Huber, J. (2000). The impact of anticipatory satisfaction on consumer choice. Journal of Consumer Research, 27, 202-216.

Sifferlin, A. (2013). My nose made me buy it: How retailers use smell (and other tricks) to get you to spend, spend, spend. Retrieved February 11, 2019 from http://healthland.time.com/2013/12/16/ my-nose-made-me-buy-it-how-retailers-use-smell-and-other-tricksto-get-you-to-spend-spend-spend/

Singh, J., Arnold, T., Brady, M., \& Brown, T. (2019). Synergies at the intersection of retailing and organizational frontlines research. Journal of Retailing, 95(2), 90-93.

Spence, C., Puccinelli, N. M., Grewal, D., \& Roggeveen, A. L. (2014). Store atmospherics: A multisensory perspective. Psychology and Marketing, 31, 472-488.

Steuer, J. (1995). Defining virtual reality: Dimensions determining telepresence. In F. Biocca \& M. R. Levy (Eds.), Communication in the age of virtual reality (pp. 33-56). Hillsdale, NJ: Lawrence Erlbaum Associates.

Stryker, S., \& Burke, P. (2000). The past, present, and future of identity theory. Social Psychology Quarterly, 63, 284-297.

Terdiman, D. (2018). How AI is helping Amazon become a trillion-dollar company. Retrieved February 11, 2019 from https://www. fastcompany.com/90246028/how-ai-is-helping-amazon-become-atrillion-dollar-company

Törn, F. (2018). Head of insights, Analytics, and Intelligence, Coop, Phone Interview, December 13, 2018.

TwentyBN (2019). Personal communication with Moritz MuellerFreitag, Chief Operating Officer of TwentyBN, at the National Retail Federation Innovation Lab, January 14, 2019.

van Doorn, J., Mende, M., Noble, S. M., Hulland, J., Ostrom, A. L., Grewal, D., \& Petersen, A. A. J. (2017). Domo Arigato Mr. 
Roboto: Emergence of automated social presence in organizational frontlines and customers' service experiences. Journal of Service Research, 20, 43-58.

Venkatesh, V., \& Davis, F. D. (2000). A theoretical extension of the technology acceptance model: Four longitudinal field studies. Management Science, 46, 186-204.

Walsh, N. (2018). The next time you order room service, it may come by robot. Retrieved February 11, 2019 from https:/www.nytimes.com/ 2018/01/29/travel/the-next-time-you-order-room-service-it-maycome-by-robot.html

Yamashita, E. (2019). Igniting emotions through AR and VR. Session at the National Retail Federation's Big Show, New York City, January 15.
Zhang, S. (2018). Grocery chains turn to automation to retain in-store customers. Retrieved February 11, 2019 from https://www. bizjournals.com/phoenix/news/2018/04/06/grocery-chains-turn-toautomation-to-retain-in.html

Zhu, L., Benbasat, I., \& Jiang, Z. (2010). Let's shop online together: An empirical investigation of collaborative online shopping support. Information Systems Research, 21, 872-891.

Publisher's note Springer Nature remains neutral with regard to jurisdictional claims in published maps and institutional affiliations. 